\title{
Multiple-level validation identifies PARK2 in the development of lung cancer and chronic obstructive pulmonary disease
}

\author{
SeungBaek Lee ${ }^{1, *}$, Jun She ${ }^{2,3, *}$, Bo Deng ${ }^{3,4, *}$, JungJin Kim ${ }^{1, *}$, Mariza de Andrade ${ }^{3}$, Jie \\ $\mathrm{Na}^{3}$, Zhifu Sun ${ }^{3}$, Jason A. Wampfler ${ }^{3}$, Julie M. Cunningham ${ }^{5}$, Yanhong $\mathbf{W u}^{5}$, Andrew \\ H. Limper ${ }^{6}$, Marie-Christine Aubry ${ }^{7}$, Chris Wendt ${ }^{8,9}$, Peter Biterman ${ }^{8}$, Ping Yang ${ }^{3}$ \\ Zhenkun Lou ${ }^{1}$ \\ ${ }^{1}$ Division of Oncology Research, Mayo Clinic, Rochester, MN, USA \\ ${ }^{2}$ Department of Pulmonary Medicine, Zhongshan Hospital, Fudan University, Shanghai, China \\ ${ }^{3}$ Department of Health Sciences Research, Mayo Clinic, Rochester, MN, USA \\ ${ }^{4}$ Department of Thoracic Surgery, Institute of Surgery Research, Daping Hospital, Third Military Medical University, Chongqing, \\ China \\ ${ }^{5}$ Genomics Shared Resource, Mayo Clinic, Rochester, MN, USA \\ ${ }^{6}$ Division of Pulmonary and Critical Care Medicine, Mayo Clinic, Rochester, MN, USA \\ ${ }^{7}$ Division of Anatomic Pathology, Mayo Clinic, Rochester, MN, USA \\ ${ }^{8}$ Department of Medicine, Pulmonary Division, University of Minnesota, Minneapolis, MN, USA \\ ${ }^{9}$ Department of Medicine, Pulmonary Section, Minneapolis VA Medical Center, Minneapolis, MN, USA \\ *These authors have contributed equally to this work \\ Correspondence to: Ping Yang, email: Yang.Ping@mayo.edu \\ Zhenkun Lou, email: Lou.Zhenkun@mayo.edu
}

Keywords: lung cancer, chronic obstructive pulmonary disease, PARK2, inflammation

Received: January 27, 2016

Accepted: May 09, 2016

Published: June 13, 2016

\section{ABSTRACT}

An important precursor to lung cancer development is chronic obstructive pulmonary disease (COPD), independent of exposure to tobacco smoke. Both diseases are associated with increased host susceptibility, inflammation, and genomic instability. However, validation of the candidate genes and functional confirmation to test shared genetic contribution and cellular mechanisms to the development of lung cancer in patients with COPD remains underexplored. Here, we show that loss of PARK2 (encoding Parkin) increases the expression of proinflammation factors as well as nuclear NF-KB localization, suggesting a role of PARK2 loss in inflammation. Additional exploration showed that PARK2 deficiency promotes genomic instability and cell transformation. This role of PARK2 in inflammation and chromosome instability provides a potential link among Parkin, COPD and lung cancer. A further comprehensive validation of 114 informative single nucleotide polymorphism (SNP) variants of PARK2, in 2,484 cases and controls with well-defined lung cancer and COPD phenotypes, found rs577876, rs6455728 and rs9346917 $(p<0.01)$ to be significantly associated with lung cancer development in people with COPD. Our findings support the evidence that PARK2 might have a tumor suppressor role in the development of COPD and lung cancer.

\section{INTRODUCTION}

Lung cancer and chronic obstructive pulmonary disease (COPD) combined, present a major cause of morbidity and mortality globally that has persisted for several decades [1-3]. These two complex diseases are closely linked to each other as shared environmental and genetic risk factors are implicated in both $[4,5]$. COPD coexists in $40-70 \%$ of patients with lung cancer and is increasingly recognized as a predecessor of lung cancer development, independent of tobacco exposure [6] and most published genetic studies focused on either 
lung cancer or COPD [5, 7-9]. Chronic inflammation plays a central role and key inflammatory cells such as macrophages, neutrophils, and $\mathrm{T}$ lymphocytes are involved in COPD [10-14]. Macrophages from COPD patients release higher levels of pro-inflammatory cytokines (TNF- $\alpha$ and IL-6) compared to nonsmoking control subjects $[15,16]$. Inflammation and COPD together are strongly associated with lung cancer but the molecular basis for inflammation and cancer has not been established yet.

Loss of function mutations in the gene PARK2 encoding Parkin, an E3 ubiquitin ligase, leads to death of dopaminergic neurons and causes Autosomal Recessive Juvenile Parkinsonism (AR-JP) [17, 18], the neuroprotective role of $P A R K 2$ is linked to mitophagy [19]. Recently, PARK2 has been suggested as a haploinsufficient tumor suppressor gene, based on the frequent deletion or mutation in human cancer [20, 21]. Consistent with this notion, overexpression of PARK2 in hepatocarcinoma, glioblastoma, lung cancer, breast cancer and colon cancer cell lines repressed cell growth [20-24]. Furthermore, PARK2-null mice displayed increased vulnerability to inflammation-induced degeneration when exposed to chronic systemic lipopolysaccharide (LPS) [25]. Cancer cell lines that harbor a deleted PARK2 gene show resistance to TNF- $\alpha$ induced cell death [16]. These observations suggest a potential function of PARK2 as a regulator of immune response. However, how PARK2 functions in immune response and its relationship to tumorigenesis remains unclear. In this study, we investigated a potential role of PARK2 in inflammation, COPD and lung cancer.

\section{RESULTS}

\section{Loss of PARK2 maintains higher expression of cytokines for inflammation}

To assess the role of PARK2 in inflammation, we generated PARK2 knockout (KO) in C57BL/6 mice and assessed IL-6 levels in mouse serum. Notably, IL-6 levels in PARK2 $\mathrm{KO}$ mice were significantly higher than those in wild type (WT) mice (Figure 1A). Similarly, mouse primary bronchus epithelial cells and mouse embryonic fibroblasts (MEFs) from PARK2 KO mice produced more IL-6 than controls (Figure 1B and 1C). Furthermore, the expression of other inflammation markers, IL- $1 \beta$ and TNF- $\alpha$ also increased in PARK2 deleted cells (Figure $1 \mathrm{~B}$ and $1 \mathrm{C}$ ). In addition, the increases caused by PARK2 KO were reversed by exogenous expression of WT PARK2 (Figure 1D). These results suggest that PARK2 has anti-inflammation functions. We also performed immunohistochemistry (IHC) in PARK2 wild type (WT) and knockout (KO) mouse at 10 months (Figure 1E). PARK2 KO mice showed increased inflammation phenotypes, as evinced by densely packed plasma cells around lung bronchia. This data suggested that PARK2 deficiency leads to increased inflammation.

\section{Overexpression of $P A R K 2$ inhibits localization of the nuclear NF- $\kappa \mathrm{B}$ for inflammation}

Nuclear factor kappa B (NF- $\kappa B)$ is a broadly expressed transcription factor that induces cytokines and immunoglobulin (Ig) gene expression in COPDrelated inflammation [26]. Although NF- $\kappa B$ is present in its inactive state in the cytoplasm, its p50-p65 heterodimer translocates to the nucleus and binds the DNA (at the promoter region) when NF- $\mathrm{KB}$ is activated by carcinogens, tumor promoters, inflammatory cytokines, and other chemotherapeutic agents [27]. To understand PARK2's role in inflammation, we monitored $\mathrm{NF}-\kappa \mathrm{B}$ localization in PARK2-depleted primary human bronchial epithelial BEAS-2B cells using fluorescence microscopy (Figure 2A and 2B) and immunoblot (Figure 2C). The depletion of PARK2 led to increased nuclear NF- $\kappa \mathrm{B}$ localization in the absence of stimuli (Figure 2A, 2B and 2C). In addition, TNF- $\alpha$ treatmentinduced nuclear NF- $\kappa \mathrm{B}$ translocation was significantly blocked by the expression of WT PARK2 (Figure 2D and 2E). Interestingly, expression of mutant $P A R K 2$ that inactivates its E3 ligase has a partial effect in blocking $\mathrm{NF}-\kappa \mathrm{B}$ translocation. These results demonstrate that PARK2 suppresses NF-kB activation in an E3 ligasedependent and -independent manner.

We next explored how PARK2 suppresses NF$\mathrm{kB}$ activation. Several papers reported involvement of PARK2 in the antioxidant defense [28, 29]. We confirmed increased Reactive oxygen species (ROS) levels in PARK2 KO MEFs (Figure 2F). ROS has been linked to increased Akt activation, and NF-kB activation [30-33]. Consistent with this, we found increased Akt S473 phosphorylation in PARK2 KO MEFs (Figure 2G). Treatment of PARK2 KO MEFs with NAC, ROS scavenger or MK 2206, Akt inhibitor (Figure $2 \mathrm{H}$ ) decreased NF-kB translocation, suggesting that PARK2 suppresses NF-kB signaling through ROS/ Akt regulation [30, 32, 33].

\section{Deletion of $P A R K 2$ induced chromosome stability and tumor initiation}

In addition to increased inflammation, PARK2 deficiency also resulted in genomic instability $[15,21$, 34]. We found that loss of PARK2 induced centrosome duplication. Using an antibody to $\gamma$-tubulin, we compared the number of centrosome in PARK2 KO and wildtype MEFs at Passage 5. Our data showed that $11 \%$ of PARK2 KO cells contained three or more centrosomes, whereas very few $W T$ MEFs have abnormal centrosomes (Figure 3A). The reconstitution of PARK2 KO cells with 
PARK2 corrected the centrosome abnormities (Figure 3B). Similar results were obtained using IMR-90 lung fibroblasts $(\mathrm{PDL}=33)$ or MEFs supporting the idea that $P A R K 2$ deficiency results in genomic instability (Figure $3 \mathrm{C}, 3 \mathrm{D}$ and $3 \mathrm{E})$.

Our results suggest that $P A R K 2$ deficiency results in increased inflammation and genomic instability, both of which are potential drivers of tumorigenesis [20, 21, 23, 25]. To confirm whether PARK2 contributes to tumorigenesis in ex-vivo models, we seeded PARK2 WT or KO MEFs in 3-D organoid culture system. Culture of cells as three-dimensional (3-D) aggregates can enhance in vitro tests for basic biological research as well as mimics tissue organization condition in vivo $[35,36]$. We found that PARK2 KO MEFs, but not WT MEFs, formed colonies in 3-D culture (Figure 4A).Furthermore, we found that PARK2 knockout MEFs became transformed and promoted cancer cell growth by foci and colony
A

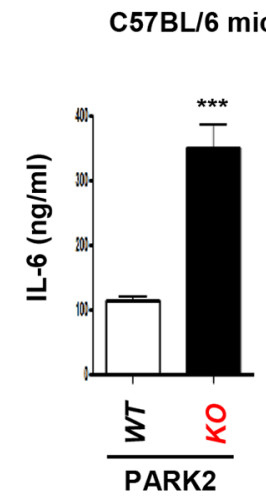

B

Mouse primary bronchus epithelial cells

\section{C}

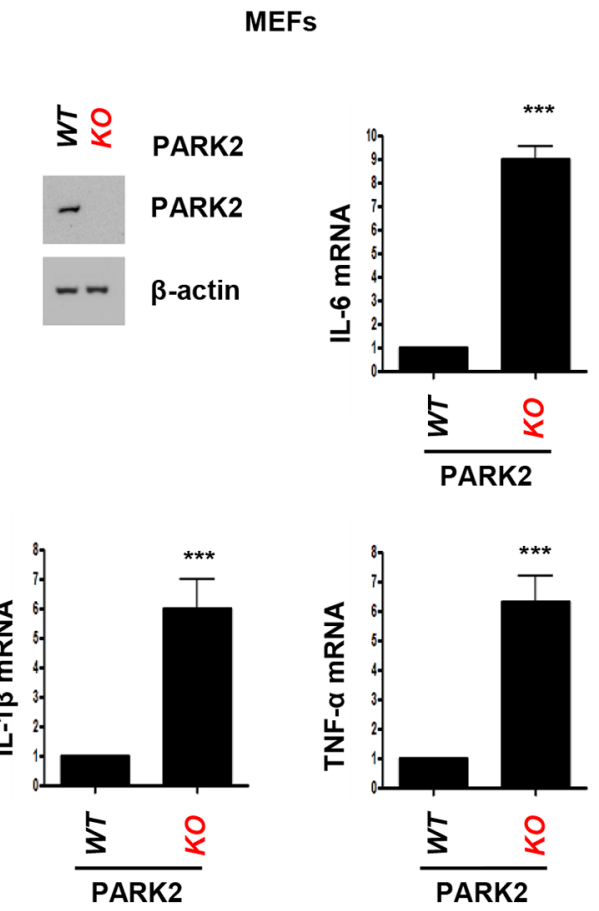

D

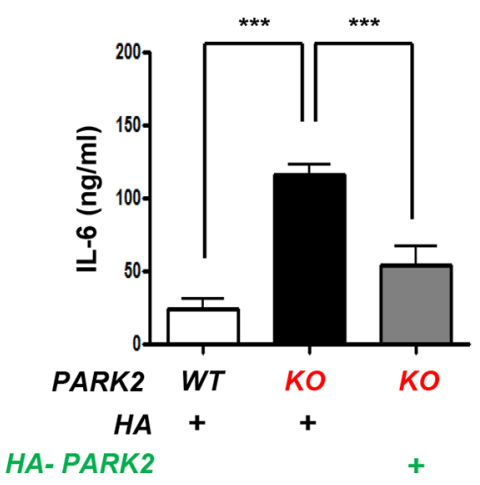

$\mathbf{E}$

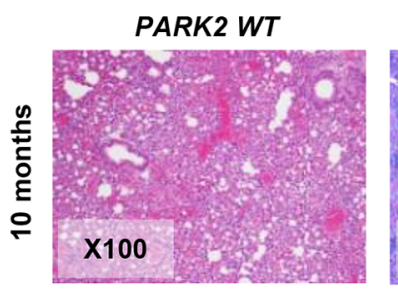

PARK2 KO

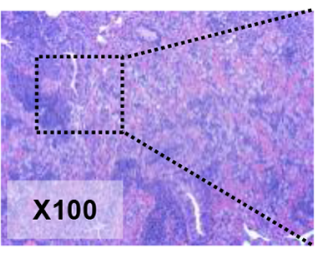

Magnification

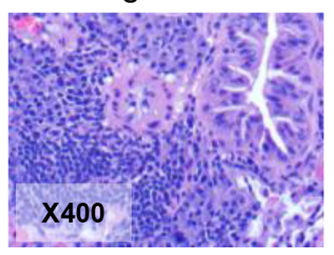

Figure 1: Loss of PARK2 maintains higher expression of cytokines for inflammation. A-C. Cytokines, IL-6, IL-1 $\beta$ or TNF- $\alpha$ protein or mRNA levels in serum from C57BL/6 mice (A), mouse primary bronchus epithelial cells (B), MEFs (C) of PARK2 WT or KO were analyzed by ELISA or qRT-PCR. D. After infection with the indicated plasmids, cytokines in the cultured MEFs supernatants were determined by ELISA. Results are shown as means $( \pm$ SEM), and at least three experiments were performed for all experiments. ***, $p<0.001$ by one-way ANOVA. E. PARK2 WT and $K O$ mice $(n=6)$ at 10 months of age were analyzed for tumor event by immunohistochemistry. H\&E staining; $\mathrm{x} 100$ and $\mathrm{x} 400$. 
A

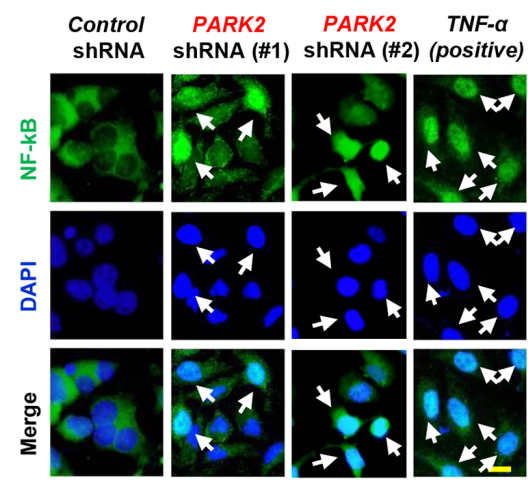

D

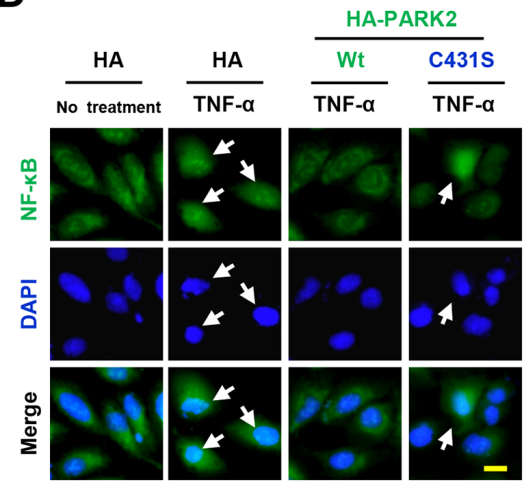

$\mathbf{F}$

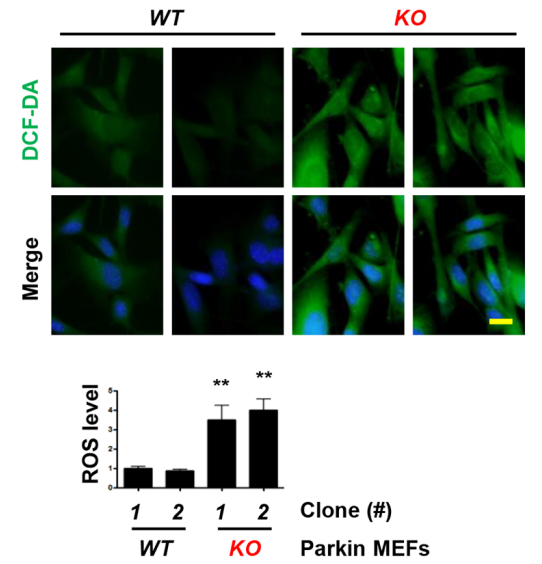

B

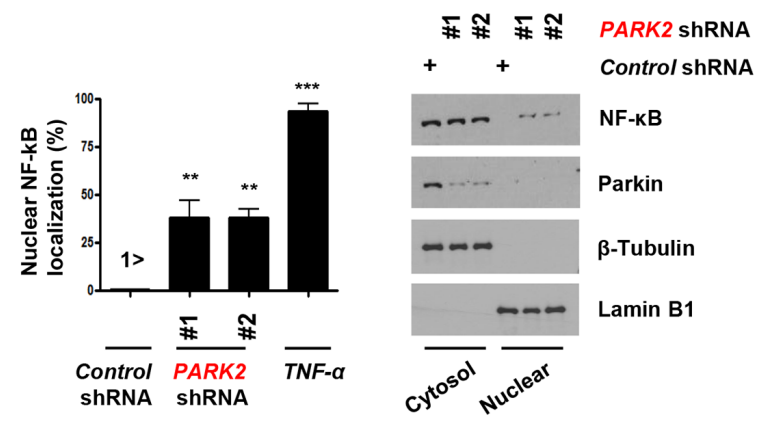

$\mathbf{E}$
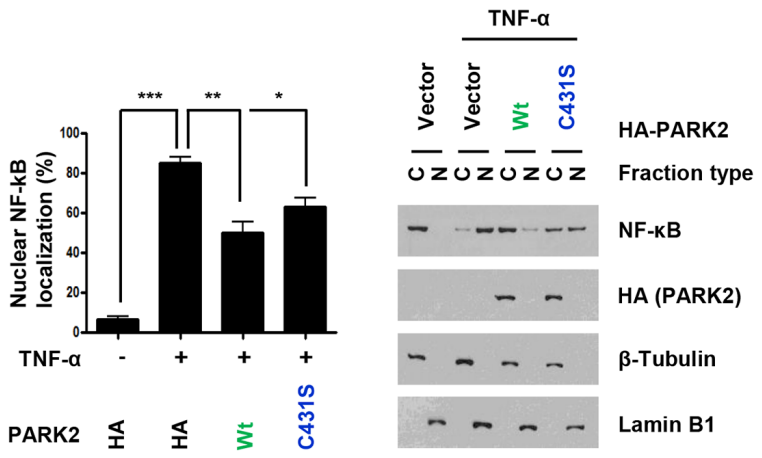

G

H
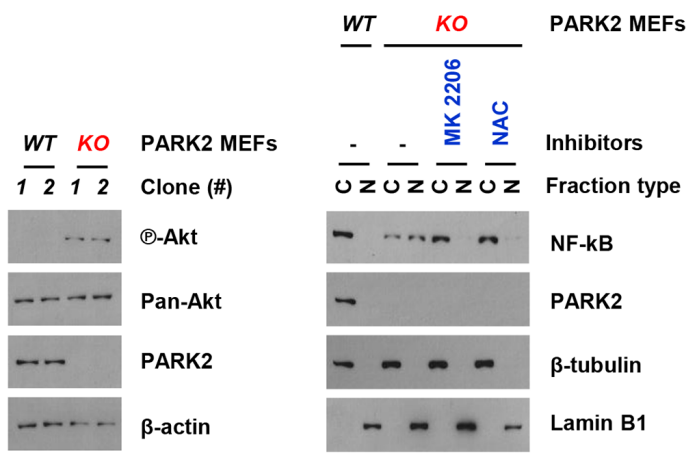

Figure 2: Overexpression of $P A R K 2$ inhibits localization of the nuclear NF- $\kappa B$ for inflammation. A-C. After infection with the indicated shRNAs, Primary and immortalized (BEAS-2B) human bronchial epithelial cell lysates were fixed for immunofluorescence assay or blotted with the indicated antibodies. (A) Representative images of the cells with indicated localization of the nuclear NF-kB (white arrows). Cells were fixed and stained with DAPI. TNF- $\alpha$-treated cells were shown as positive controls. Scale bar, $20 \mu \mathrm{m}$. (B) Analysis of numerical nuclear NF-kB events. 100 cells were counted in each experiment. ${ }^{* *}, p<0.01$ and ${ }^{* * *}, p<0.001$ by one-way ANOVA. (C) Immunoblot analysis with indicated antibodies after nuclear fractionation. D. After transfection with the indicated plasmids, Beas-2B cells were selected by G418 to select stable transfectants, cells were treated with TNF- $\alpha$ and cells lysates were fixed for immunofluorescence assay or cell lysates were analyzed immunobloting. Representative images of the cells with indicated localization of the nuclear NF$\kappa \mathrm{B}$ (white arrows). Cells were fixed and stained with DAPI. TNF- $\alpha$-treated cells were shown as negative controls. Scale bar, $20 \mu \mathrm{m}$. Quantification of the nuclear NF- $\mathrm{kB}$ localization. Results are shown as means ( \pm SEM), and at least three experiments were performed for all experiments. ${ }^{*}, p<0.05,{ }^{* *}, p<0.01$ and ${ }^{* * *}, p<0.001$ by one-way ANOVA. E. After nuclear fractionation, NF-kB, Lamin B1 and $\beta$-tubulin expression was measured by immunoblot. Lamin B1, nuclear marker; $\beta$-tubulin, cytosol marker. F. Cells were stained with DCF-DA, fixed and analyzed by immunofluorescence. G. Cells were harvested and analyzed by immunobloting. H. Cells were treated with the indicated chemicals, MK 2206 (an allosteric Akt inhibitor) or NAC (ROS scavenger). After nuclear fractionation, NF-kB, Lamin B1 and $\beta$-tubulin expression was measured by immunoblot. Lamin B1, nuclear marker; $\beta$-tubulin, cytosol marker. 
A

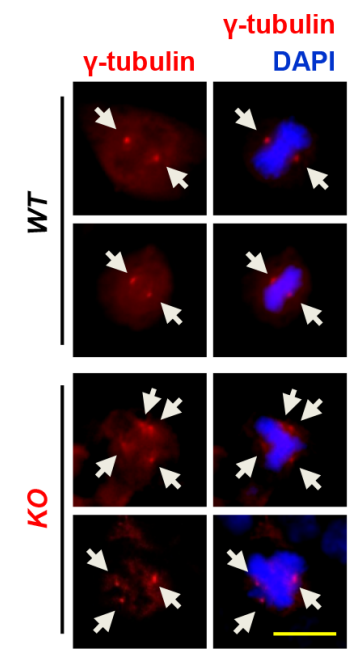

B
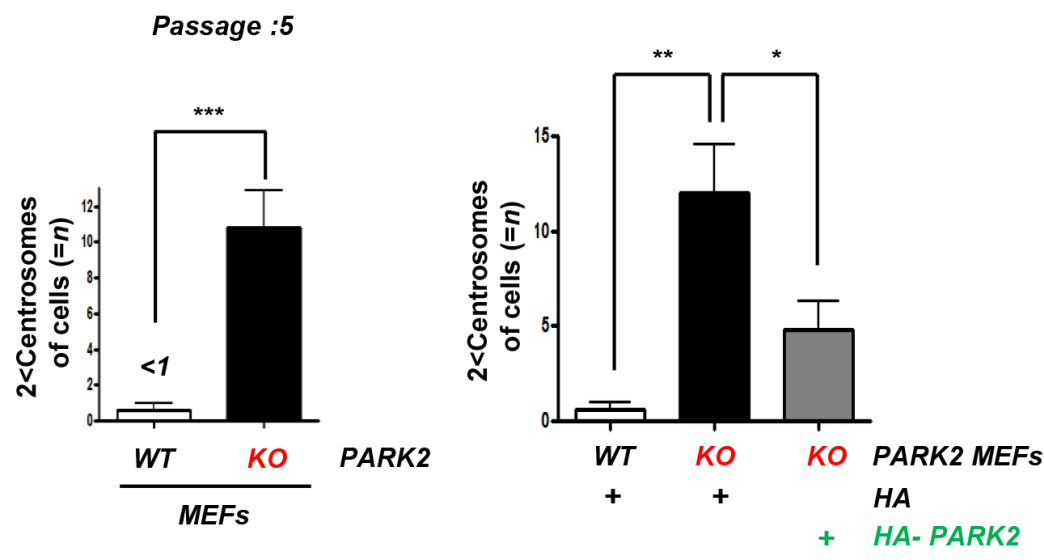

C

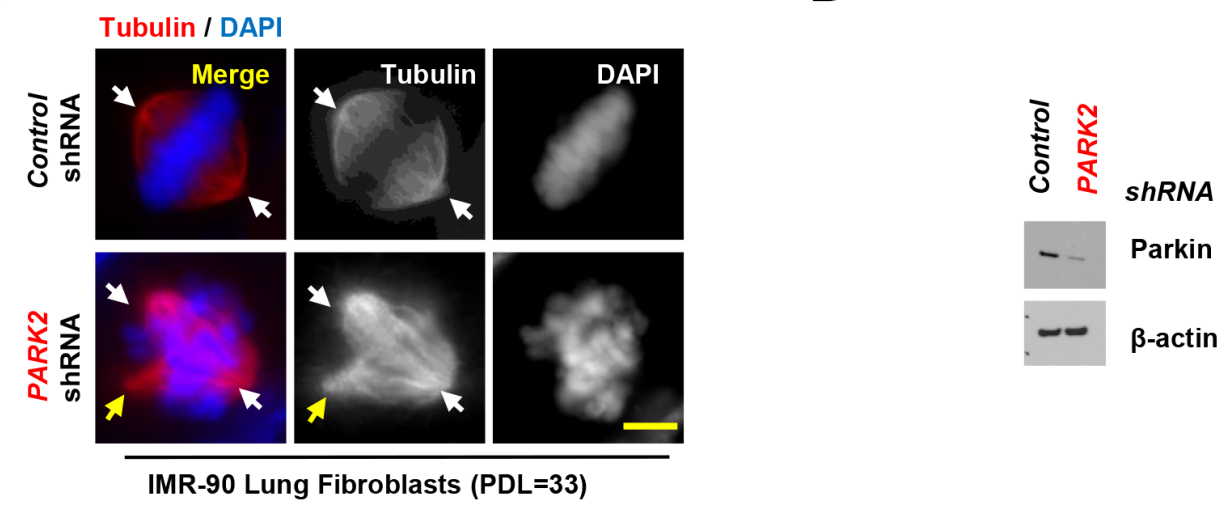

E
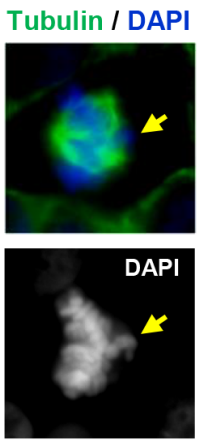
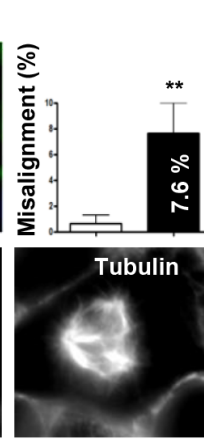

Tubulin / DAPI
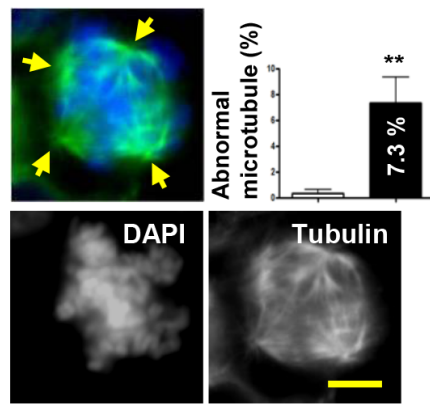

Mouse Embryonic Fibroblast (Passage : 5)

PARK2 ${ }^{+}$

PARK2 \%

Figure 3: Deletion of $\boldsymbol{P A R K 2}$ induced chromosome instability. A. PARK2 deficiency results in centrosome amplification in MEFs at passage 5. (left) Immunofluorescence staining shows impaired mitoses in MEFs depleted of PARK2. Red, $\gamma$-tubulin; White arrows, centrosome in mitosis. The scale bar is $20 \mu \mathrm{m}$. (right) Quantification of $2<$ centrosomes cells. ***, $p<0.001$ by one-way ANOVA. $n=10$. B. After infection with the indicated plasmids, MEFs lysates were fixed for immunofluorescence assay. Quantification of $2<$ centrosomes cells using $\gamma$-tubulin. Results are shown as means $( \pm$ SEM), and at least three experiments were performed for all experiments. $*, p<0.05$ and $*^{*}, p<0.01$ by one-way ANOVA. C. Immunofluorescence staining shows impaired mitoses in IMR 90 lung fibroblast cells depleted of PARK2. White arrows, centrosome in mitosis. Yellow arrows, abnormal chromosome. The scale bar is $20 \mu \mathrm{m}$. D. Cell were harvested at indicated times and analyzed by immunobloting. E. Impaired mitoses including multipolar spindles, misalignment and abnormal microtubule in PARK2 knockout (KO) MEF cells. Yellow arrows, abnormal chromosome. The scale bar is $20 \mu \mathrm{m}$. Results are shown as means $( \pm \mathrm{SEM})$, and at least three experiments were performed for all experiments. ${ }^{* *}, p<0.01$ by one-way ANOVA. 
A

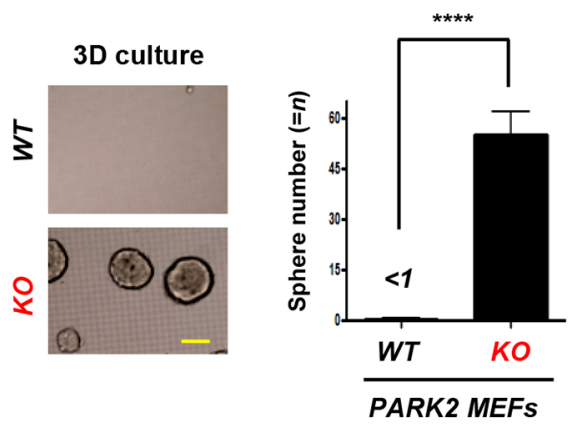

C

Colony forming assay Passage :21
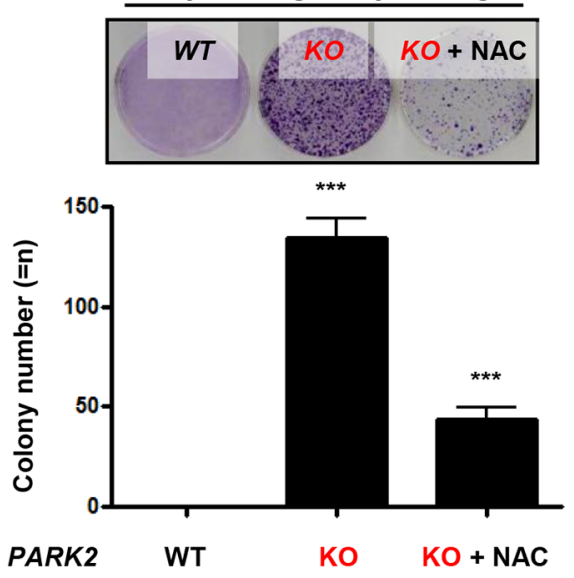

$\mathbf{E}$

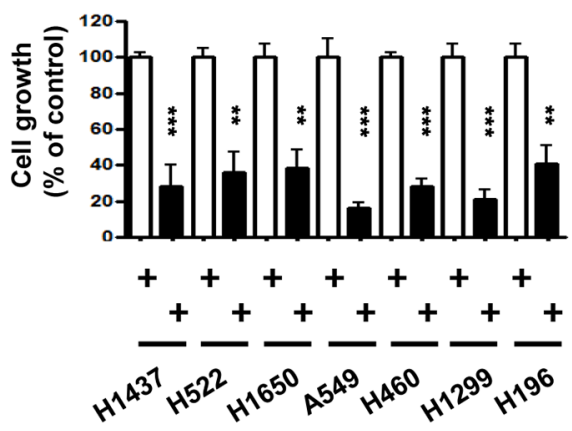

B

Transformation assay (for foci)
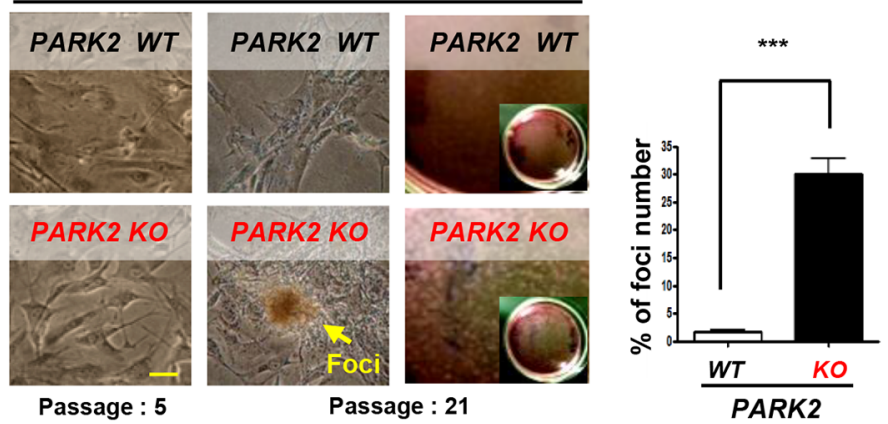

D
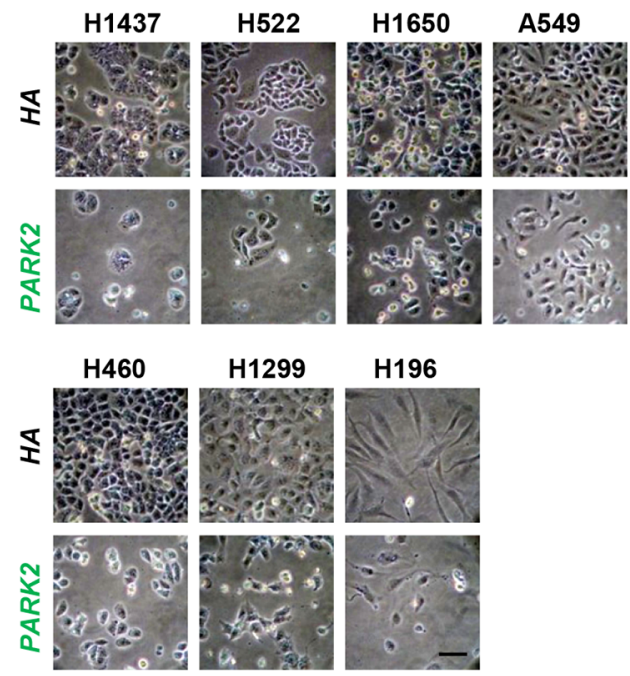

$\mathbf{F}$

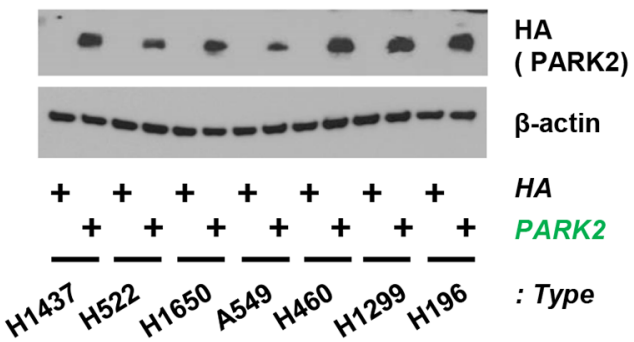

Figure 4: PARK2 loss leads to tumor initiation and overexpression of $P A R K 2$ inhibits cell proliferation in lung cancer cell lines. A. Primary MEFs were applied on 3-D cultures system for 2 weeks and counted the sphere of the cells. (top) Representative images indicate the sphere cells. (bottom) Quantification of the sphere number. $* * * *, p<0.0001$ by one-way ANOVA. $n=6$. (B. and C.) PARK2 WT and KO MEFs were analyzed for foci formation at passage 5 and 21 (B), and colony formation at passage $21 \mathbf{C}$. The scale bar is $20 \mu \mathrm{m}$. Results are shown as means ( \pm SEM), and at least three experiments were performed for all experiments. NAC, ROS scavenger. ***, $p<0.001$ by one-way ANOVA. D. The growth of lung cancer cell lines (H1437, H522, H1650, A549, H460, H1299 and H196) was inhibited through infection with PARK2. Cells were transfected with the indicated plasmids, and then cell lysates were blotted with the indicated antibodies. E. The percentage of lung cancer cell growth compared to controls after transfected PARK2. Results shown as means $( \pm \mathrm{SEM})$, and at least three experiments were performed for all experiments. ${ }^{* *}, p<0.01$ and ${ }^{* * *}, p<0.001$ by one-way ANOVA. F. PARK2 and $\beta$-actin expression was measured by immunoblot. 
formation assay, where the frequency of foci number and colony number were increased (Figure $4 \mathrm{~B}$ and $4 \mathrm{C}$ ), suggesting a role of $P A R K 2$ loss in tumor initiation. Treatment of PARK2-deficient MEFs with N-acetyl-1cysteine (NAC), ROS scavenger, significantly decreased colony formation, suggesting that ROS is a contributing factor in cellular formation induced by $P A R K 2$ loss. We next examined the potential role of PARK2 on the growth of lung cancer cells. After the PARK2 gene was expressed in seven lung cancer cell lines (H1437, H522, H1650, A549, H460, H1299 and H196), the growth of tumor cell lines was significantly inhibited compared to controls (Figure 4D, 4E and 4F), which suggests that $P A R K 2$ overexpression plays a critical role in the inhibition of lung cancer cell proliferation [28]. Multiple PARK2 mutations have also been identified in human lung cancer (Supplementary Table S1). These results suggest that PARK2 deficiency might contribute to lung cancer development.

\section{$P A R K 2$ as a potential target to reduce the risk of COPD and lung cancer}

As $P A R K 2$ deficiency results in both increased inflammation and genomic instability [37-39], we assessed a potential role of PARK2 in lung cancer and COPD through a comprehensive validation study of 114 informative single nucleotide polymorphism (SNP) variants of PARK2 (Supplementary Table S2 ) in 2,484 cases and controls with well-defined lung cancer (LC) and COPD phenotypes (Table 1). For specific comparisons, we assigned the four groups into the six models as follows: Model 1: LC+COPD+ vs. LC-COPD(cases with both compared to controls with neither); Model 2: LC+COPD- vs. LC-COPD- (cases with LC compared to controls with neither); Model 3: LC-COPD+ vs. LC-COPD- (cases with COPD compared to controls with neither); Model 4: LC+COPD+ vs. LC-COPD+ (cases with both compared to controls with COPD); Model 5: LC+ vs. LC- (LC cases compared to LCfree controls, adjusting for COPD and other covariates including age, sex, and smoking history); and Model 6: COPD + vs. COPD- (COPD cases compared to COPDfree controls, adjusting for LC and other covariates including age, sex, and smoking history). After using two methods of minimizing false positive results and a penalized logistic regression analysis [40-42], rs577876, rs6455728 and rs9346917 $(p<0.01)$ were confirmed to be associated with lung cancer development in people with COPD (in Model 4 only, Table 2 ). Figure 5 shows the LD haplotype blocks of five SNPs that were tested significant in Model 4. Noted is rs34424986 [24, 43], which lies between rs2223468 and rs9346917.

This is the first study that presents lung cancer with COPD as a separate disease entity from the lung cancer or COPD phenotype [44]. We found the PARK2 gene associates with the phenotype of lung cancer with COPD, compared to COPD patients. Notably, altered PARK2 expression induced chromosomal instability and increased inflammation, similar to that found in the COPD phenotype. We demonstrated that PARK2 may be a bona fide tumor suppressor gene that may be responsible for the development of progression lung cancer with COPD, suggesting PARK2 as a potential target to reduce the risk of COPD and lung cancer. Our results evinced the biological plausibility as well as the common and unique mechanisms in lung cancer with COPD development [45].

\section{DISCUSSION}

Our analysis of PARK2, located at 6q25.2-q27, revealed four significant yet independent SNPs to be associated with lung cancer with COPD. Although the function of PARK2 in lung cancer remains unknown, we suggest that PARK2-deficiency induced inflammation and genomic instability are possible factors contributing to lung cancer. PARK2 mutations are known to cause Parkinson's disease and have also been identified in human malignancies, including lung cancer, and are associated with the potential to inhibit cancer cell growth in vitro [21], suggesting that PARK2 may function as a tumor suppressor gene. Additionally, a SNP in PARK2 was associated with a decline in forced expiratory volume in 1 second (FEV1) and a recurrent PARK2 mutation was recently reported $[24,46]$. Our study demonstrated that PARK2 expression significantly inhibited cell growth in lung cancer cells lines compared to controls, while abnormal inflammation and cell division was induced by PARK2 deficiency. This result could be interpreted as a role in cancer initiation, progression or both. As inflammation and chromosomal instability are a driving forces for tumor initiation, it is possible that PARK2 mutation/loss may also involved in lung cancer progression and prognosis (Supplementary Figure S1).

In conclusion, our multi-level validation study suggests a critical role of PARK2 in the development of lung cancer with COPD. We showed that PARK2 inhibiting role in inflammation, lung cancer cell growth, and the chromosomal instability that might contribute to tumor initiation when PARK2 expression is altered. We used strict inclusion criteria in the study. Lung cancer diagnoses were re-confirmed by pulmonary pathologists and COPD was confirmed by lung function testing. The definition of COPD phenotype based on lung function tests minimizes the phenotypic heterogeneity caused by the use of clinical records or patient reported symptoms. As a result, the reliability and validity of our study is sound. These findings have advanced the current understanding of the development of lung cancer with COPD, and the progression from COPD to lung cancer, potentiating the discovery of new targets for prevention, early diagnosis, and treatment. 
Table 1: Distribution of lung cancer (LC) and chronic obstructive pulmonary diseases (COPD) in 2484 cases and controls

\begin{tabular}{lccc}
\hline & COPD + & COPD - & Total \\
\hline $\mathrm{LC}+$ & $\mathrm{n}+/+(573)$ & $\mathrm{n}+/-(612)$ & 1185 \\
$\mathrm{LC}-$ & $\mathrm{n}-/+(537)$ & $\mathrm{n}-/-(762)$ & 1299 \\
Total & 1110 & 1374 & 2484 \\
\hline
\end{tabular}

Table 2: Significant results of Testing 114 Informative PARK2 SNPs

\begin{tabular}{|c|c|c|c|c|c|c|}
\hline \multirow{2}{*}{\multicolumn{2}{|c|}{$\begin{array}{l}\text { PARK2 Gene } \\
\text { (Chromosome 6)SNP rs-ID }\end{array}$}} & \multirow{2}{*}{$\begin{array}{l}\text { Alleles(major: } \\
\text { minor) }\end{array}$} & \multirow{2}{*}{$\begin{array}{c}\text { MAF } \\
\text { controls* }\end{array}$} & \multirow{2}{*}{$\begin{array}{l}\text { MAF } \\
\text { cases* }\end{array}$} & \multicolumn{2}{|c|}{ Penalized regression } \\
\hline & & & & & OR & P-value \\
\hline PARK2 & rs577876 & $A: G$ & 0.41 & 0.35 & 0.73 & $5.49 \times 10^{-4}$ \\
\hline PARK2 & rs6455728 & G:T & 0.29 & 0.24 & 0.70 & $3.28 \times 10^{-3}$ \\
\hline PARK2 & rs9346917 & $\mathrm{C}: \mathrm{T}$ & 0.35 & 0.30 & 0.68 & $1.66 \times 10^{-3}$ \\
\hline
\end{tabular}

* MAF is Minor Allele Frequency calculated from the controls (LC+COPD-) and cases (LC+COPD+).

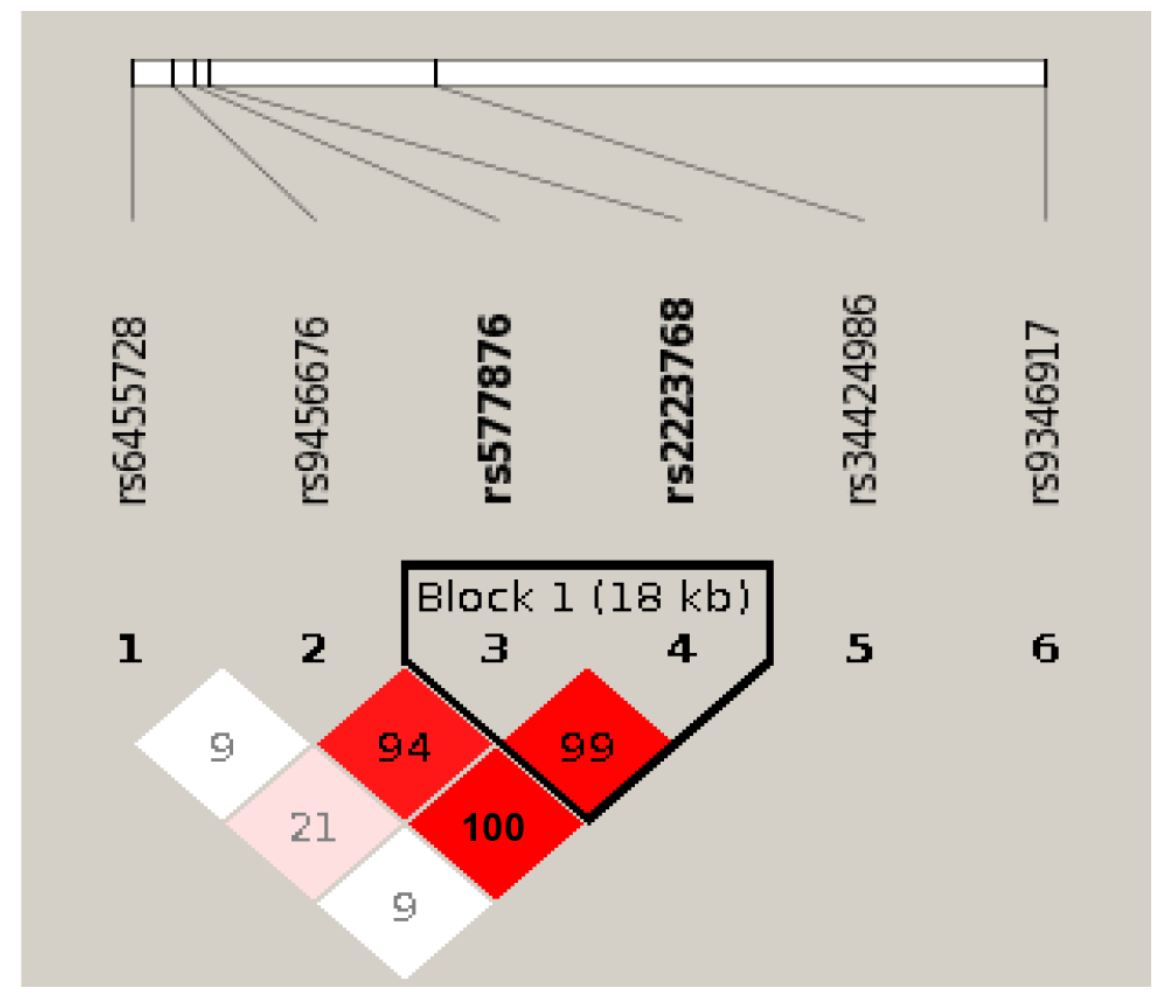

Figure 5: Linkage disequilibrium (LD) plot of 6 SNPs in PARK2 gene. Among the six SNPs, five (SNPs 1-4 and 6) are tested significant in our Model 4 that comparing cases with lung cancer and chronic obstructive pulmonary diseases (COPD) to controls with COPD only. One SNP rs34424986, which was recently reported from an independent study [24] but not included on GWAS panels, is shown relative position among the five tested significant SNPs. Numbers shown in blocks are D' values (i.e., D'x100; 99 means D' = 0.99), which measures the strength of LD between two neighboring SNPs. The higher of D' value, the more statistically associated between two SNPs. Because the high LD between rs9456676, rs577876 and rs2223768, final results of penalized regression model removed two SNPs (rs9456676 and 2223768). LOD, means logarithm of odds score, is a statistical test used in genetic linkage analysis. Legends: White D' $<1$, LOD $<2$; Pink shades - D' $<1$, LOD $\geq 2$; Red - D' $=1$, LOD $\geq 2$; None: SNPs not correlated. 


\section{MATERIALS AND METHODS}

\section{Mouse strains and MEFs}

All animal procedures were approved by the Institutional Animal Care and Use Committee which also approved experimental procedures. Mouse strains were described previously [34, 47]. PARK2 KO C57BL/6 (6-8 weeks old, female) mice were purchased from the Jackson Laboratory (Bar Harbor, ME, USA) and mated. Mouse embryonic fibroblasts were isolated from individual day 11.5-13.5 (E11.5 - E13.5) embryos by uterine dissection. Each embryo was washed gently with 1x PBS ( $\mathrm{pH} 7.2$ ), followed by removal of the mouse embryo's head and liver. The embryo body was suspended in $0.5 \mathrm{ml}$ of $0.25 \%$ Trypsin-EDTA, and then forced through a $1 \mathrm{ml}$ syringe with an 18-gauge needle. The tissue homogenate was incubated for 30 min at $37{ }^{\circ} \mathrm{C}$, triturated by drawing the suspension through a pipette, and then evenly divided into two 10 cm tissue culture dishes in Dulbecco's modified Eagle's medium (DMEM) with $15 \%$ fetal bovine serum (FBS). Early-passage MEFs (passage 1-5) were used for all experiments, and at least three lines were examined for all studies. Animals were housed in a pathogen-free barrier environment throughout the study.

\section{Cells and cell lines and reagent}

All cell lines were sourced from the American Type Culture Collection (ATCC, Manassas, VA). These included seven lung cancer cells, H1437, H522, H1650, A549, H460, H1299 and 196, and one normal human lung fibroblast cell line, IMR-90. c. For the human lung fibroblast IMR-90 cells ranging from 29 to 34 in population doubling level (PDL) were used. Cell lines were maintained in Eagle's minimal essential media (EMEM, Gibco-Invitrogen, Grand Island, NY) and contained $10 \%$ (15\% for IMR-90 cells) heat-inactivated FBS (Gibco-Invitrogen), sodium bicarbonate $(2 \mathrm{mg} / \mathrm{ml}$; Sigma-Aldrich, St Louis, MO), penicillin (100 units/ $\mathrm{ml})$, and streptomycin $(100 \mu \mathrm{g} / \mathrm{ml}$; Gibco-Invitrogen $)$. An ELISA kit (R\&D Systems) was used to assay IL-6 production, according to the manufacturer's instructions. The concentrations of IL-6 were normalized to the cell numbers in the cell culture. 2', 7'- dichlorofluorescein diacetate (DCF-DA) was obtained from Molecular Probes. MK 2206 was obtained from selleckchem. $\mathrm{N}$-acetylcystein (NAC) was obtained from GibcoInvitrogen.

\section{Immunoblotting and antibodies}

For immunoblotting, extraction of proteins from cultured cells with a modified buffer was followed by immunoblotting with corresponding antibodies. Briefly, protein samples were fractionated on $10-15$ $\%$ SDS polyacrylamide gels and electroblotted onto Hybond ECL nitrocellulose membranes (Amersham Pharmacia Biotech) using a semidry transfer apparatus (Bio-Rad). Rabbit polyclonal antibodies recognizing PARK2 (ab15954), were obtained from Abcam. Mouse monoclonal antibody recognizing PARK2 (sc-32282) and Lamin B1 (sc-20682) were purchased from Santa Cruz Biotechnology. Rabbit polyclonal antibody recognizing NF- $\kappa \mathrm{B}$ (sc-372) was obtained from Santa Cruz Biotechnology. Anti- $\beta$-tubulin and HA mouse antibodies were purchased from Sigma.

\section{Immunofluorescence}

For immunofluorescence staining, MEF or IMR90, Beas-2B cells were plated on glass coverslips and transfected with the indicated constructs. Cells were then fixed in $3.7 \%$ Paraformaldehyde for 10 min at room temperature and stained using standard protocols. Immunofluorescence images were taken using fluorescent microscopy (Nikon Microscope, Melville, New York).

\section{Plasmid and gene silencing by lentiviral shRNAs}

The pMX retroviral vector containing the human cDNAs for HA-PARK2 was obtained from Addgene (plasmid 38248, Cambridge, MA). PARK2 vectors were obtained from Sigma-Aldrich and Open Biosystems.

\begin{tabular}{lllcl}
\hline Company & Species & Clone Set ID & Names & Target sequence (5'- -3') \\
Open Bio. & Human & NM_013988 & 84517 & 5'-GAGAGAGTTCTCACATTTAAT-3' \\
Open Bio. & Human & NM_013988 & 84518 & 5'-ACTCACTAGAATATTCCTTAT -3' \\
Open Bio. & Human & NM_013988 & 84520 & 5'-GAACGTTTAGAAATGATTTCAAA -3' \\
Sigma (TRC1) & Human & NM_013988 & 2399 & 5'-CGTGAACATAACTGAGGGCAT-3' \\
Sigma (TRC1) & Human & NM_013988 & 341 & 5'-CGCAACAAATAGTCGGAACAT-3' \\
Sigma (TRC1) & Human & NM_013988 & 425 & 5'-CGTGATTTGCTTAGACTGTTT-3' \\
Sigma (TRC1) & Human & NM_013988 & 434 & 5'-CTTAGACTGTTTCCACTTATA-3' \\
Sigma (TRC1) & Human & NM_013988 & 872 & 5'-CTCCAAAGAAACCATCAAGAA-3' \\
\hline
\end{tabular}




\section{Colony formation or foci assay}

For colony formation or foci assay, early-passage MEFs (passage 5) cells were plated at low density into $60-\mathrm{mm}$ cell culture plates. When sufficient colonies were visible, typically after 2-3 weeks, cells were washed twice in PBS before fixing in ice-cold $70 \%$ methanol for $30 \mathrm{~min}$, stained by $0.2 \%$ Crystal violet for 2-3 h. The following day cells were rinsed in PBS and air-dried.

\section{Cell fractionation assay}

Cell preparations were described previously. [31] The Nuclear extract kit (California, USA) was used to perform cellular fractionation in accordance with the manufacturer's instructions. The purity of the extract was confirmed by western blot analysis against anti-cytosolspecific-tubulin-actin (Sigma-Aldrich) or anti-nuclearspecific-Lamin B1.

\section{3-dimensional (3-D) organoid culture Assay}

For 3-dimensional (3-D) assays, PARK2 WT or KO MEFs were cultured on NanoCulture plates (SCIVAX Corp.). After seeding cells, cell were cultured in same condition with 2-D culture and observe cell images and recover sample 0, 3, 5, 7 days after seeding. Cells were lysed in Spheroid Lysis Buffer (Scivax).

\section{Phenotype definitions}

Lung cancer cases were pathologically diagnosed as defined by the World Health Organization [48]. COPD diagnosis was based on the criteria of the Global Initiative for Chronic Obstructive Lung Disease (GOLD) [49], i.e., subjects with a FEV1/FVC $<70 \%$ by lung function test (PFT) as COPD + regardless of sub-groups (emphysema and/or chronic bronchitis). All subjects provided written informed consent, and the study protocol was approved by the Mayo Clinic Institutional Review Board.

\section{Experimental design for PARK2 SNPs validation}

\section{Subject selection and detailed phenotyping}

A total of 2,484 well-defined subjects were included in the current study following a 4-step sampling strategy in order to minimize the confounding factors and maximize the uncommon groups: [1] enriching never-smoking cases; [2] balancing three phenotype groups, i.e., COPD only ( $\mathrm{COPD}+)$, lung cancer only $(\mathrm{LC}+)$, both $\mathrm{COPD}$ and lung cancer $(\mathrm{LC}+\mathrm{COPD}+)$ and controls (LC-COPD-); [3] matching on current vs. former smoking history with gender and age; and [4] for former smokers, matching on quitting years. To minimize the heterogeneity due to population stratification, we restricted our study to subjects of European descent [9, 44, 50-52]. In total, the study consisted of 612 with $\mathrm{LC}+, 537 \mathrm{COPD}+, 573$ $\mathrm{LC}+\mathrm{COPD}+$, and 762 controls; yielding 1,110 COPD cases and 1,185 lung cancer cases.

\section{Genome wide analysis and candidate SNPs validation}

Using GWAS Data from two Illumina platforms (OmniExpress, 610k and 370k Human BeadChips; Illumina, San Diego, California, USA) we performed genome-wide association analyzes using the models described above Concordance between platforms was $>$ $99.5 \%$. We removed samples with genotyping call rates $<95 \%$ from structure analysis. SNP quality control removed SNPs with a call rate $<95 \%$, minor allele frequencies $(\mathrm{MAF})<0.01$, Hardy-Weinberg equilibrium test $p<0.0001$. A quantile-quantile plot was generated using logistic regression for additive genetic model, and 4 sets of above-defined group comparisons of genomic inflation factors $\left(\lambda_{\mathrm{GC}}\right)$ were $1.006,1.011,0.98122$, 0.98185 , respectively. A total of 114 candidate SNPs for the PARK2 gene were matched in our genotyping platforms, after removing the redundant SNPs using linkage disequilibrium (LD) test $\left(\mathrm{r}^{2} \geq 0.8\right)$ [53].

\section{Real time PCR}

RNA preparation, cDNA, and qRT-PCR were described previously [31]. The following primers were used:

Primers Used for Real-Time PCR

IL-6 Primer sequence: Forward 5'-CCTGCGTTTAAATA ACATCAGCTTTAGCTT-3', Reverse 5'-GCACAATGTGACGT CGTTTAGCATCGAA-3',

IL-1 $\beta$ Primer sequence: Forward 5'-CACAGCAGCA CATCAACAAG-3', Reverse 5'-GTGCTCATGTCCT CATCCTG-3',

TNF- $\alpha$ Primer sequence: Forward 5'-CCAGCCAGCAG AAGCTCCCTCAGCGAG-3', Reverse 5'-GCGGATCATGCT TTCTGTGCTCATGGTGTC-3'

\section{Statistical analysis}

Each assay was performed in triplicate and independently repeated at least three times. The results are presented as mean \pm standard error of mean (SEM). Statistical analyses were performed using GraphPad Prism software (version 4.02; GraphPad Software, San Diego, CA). One-way analysis of variance (ANOVA) followed by T-test was used to compare the results. A difference was considered significant if $P<0.05$. Statistical significance was defined as $p<0.05\left(^{*}\right), p<0.01\left(^{* *}\right)$, and $p<0.001\left(^{* * *}\right)$. 


\section{ACKNOWLEDGMENTS}

The study was supported by the National Heart, Lung, and Blood Institute (NHLBI) grant, R01HL107612 (Yang and Wendt), and National Cancer Institute grants, R01-CA80127 (Yang), R01-CA84354 (Yang), R01-CA130996 (Lou), R01-CA108961 (Lou) and R01-CA148940 (Lou), and Mayo Clinic Foundation Funds (Yang and Lou), Mayo Clinic Cancer Center grant CA15083. We thank Dr. Thomas C. Smyrk (Mayo clinic) for IHC analysis. Jun She was supported by the National Natural Science Foundation for Young Scholars of China, No. 81200051 and Scientific Project for Fudan University, No. 20520133474. Bo Deng was supported by National Natural Science Foundation of China, No. 81101782 and Third Military Medical University MiaoPu project. Ola Larsson was supported by the Swedish Research Council and the Wallenbberg Academy Fellows Programme. Andrew Limper was supported by funds from the Annenberg Foundation. Biospeciens accessioning and processing, genotyping and RNA microarray analysis were supported partly by the Mayo Clinic Cancer Center grant CA15083.

\section{CONFLICTS OF INTEREST}

The authors declare no conflict of interest.

\section{REFERENCES}

1. Wang H, Dwyer-Lindgren L, Lofgren KT, Rajaratnam JK, Marcus JR, Levin-Rector A, Levitz CE, Lopez AD and Murray CJ. Age-specific and sex-specific mortality in 187 countries, 1970-2010: a systematic analysis for the Global Burden of Disease Study 2010. Lancet. 2012; 380:2071-2094.

2. Zhong N, Wang C, Yao W, Chen P, Kang J, Huang S, Chen B, Wang C, Ni D, Zhou Y, Liu S, Wang X, Wang D, Lu $\mathrm{J}$, Zheng $\mathrm{J}$ and Ran P. Prevalence of chronic obstructive pulmonary disease in China: a large, population-based survey. American journal of respiratory and critical care medicine. 2007; 176:753-760.

3. She J, Yang P, Hong Q and Bai C. Lung cancer in China: challenges and interventions. Chest. 2013; 143:1117-1126.

4. Yang P, Sun Z, Krowka MJ, Aubry MC, Bamlet WR, Wampfler JA, Thibodeau SN, Katzmann JA, Allen MS, Midthun DE, Marks RS and de Andrade M. Alpha1antitrypsin deficiency carriers, tobacco smoke, chronic obstructive pulmonary disease, and lung cancer risk. Archives of internal medicine. 2008; 168:1097-1103.

5. Soler Artigas M, Wain LV, Repapi E, Obeidat M, Sayers I, Burton PR, Johnson T, Zhao JH, Albrecht E, Dominiczak AF, Kerr SM, Smith BH, Cadby G, Hui J, Palmer LJ, Hingorani $\mathrm{AD}$, et al. Effect of five genetic variants associated with lung function on the risk of chronic obstructive lung disease, and their joint effects on lung function. American journal of respiratory and critical care medicine. 2011; 184:786-795.

6. Young RP, Hopkins RJ, Christmas T, Black PN, Metcalf $P$ and Gamble GD. COPD prevalence is increased in lung cancer, independent of age, sex and smoking history. The European respiratory journal. 2009; 34:380-386.

7. Subramanian $J$ and Govindan R. Lung cancer in never smokers: a review. Journal of clinical oncology. 2007; 25:561-570.

8. McKay JD, Hung RJ, Gaborieau V, Boffetta P, Chabrier A, Byrnes G, Zaridze D, Mukeria A, SzeszeniaDabrowska N, Lissowska J, Rudnai P, Fabianova E, Mates D, Bencko V, Foretova L, Janout V, et al. Lung cancer susceptibility locus at 5p15.33. Nature genetics. 2008; 40:1404-1406.

9. Li Y, Sheu CC, Ye Y, de Andrade M, Wang L, Chang SC, Aubry MC, Aakre JA, Allen MS, Chen F, Cunningham JM, Deschamps C, Jiang R, Lin J, Marks RS, Pankratz VS, et al. Genetic variants and risk of lung cancer in never smokers: a genome-wide association study. The Lancet Oncology. 2010; 11:321-330.

10. Barnes PJ. Immunology of asthma and chronic obstructive pulmonary disease. Nature reviews Immunology. 2008; 8:183-192.

11. Barnes PJ, Shapiro SD and Pauwels RA. Chronic obstructive pulmonary disease: molecular and cellular mechanisms. The European respiratory journal. 2003; 22:672-688.

12. Hogg JC, Chu F, Utokaparch S, Woods R, Elliott WM, Buzatu L, Cherniack RM, Rogers RM, Sciurba FC, Coxson $\mathrm{HO}$ and Pare PD. The nature of small-airway obstruction in chronic obstructive pulmonary disease. The New England journal of medicine. 2004; 350:2645-2653.

13. Jeffery PK. Comparison of the structural and inflammatory features of COPD and asthma. Giles F. Filley Lecture. Chest. 2000; 117:251S-260S.

14. Saetta M, Turato G, Baraldo S, Zanin A, Braccioni F, Mapp CE, Maestrelli P, Cavallesco G, Papi A and Fabbri LM. Goblet cell hyperplasia and epithelial inflammation in peripheral airways of smokers with both symptoms of chronic bronchitis and chronic airflow limitation. American journal of respiratory and critical care medicine. 2000; 161:1016-1021.

15. Shapiro SD. The macrophage in chronic obstructive pulmonary disease. American journal of respiratory and critical care medicine. 1999; 160:S29-32.

16. Pauwels RA, Buist AS, Calverley PM, Jenkins CR and Hurd SS. Global strategy for the diagnosis, management, and prevention of chronic obstructive pulmonary disease. NHLBI/WHO Global Initiative for Chronic Obstructive Lung Disease (GOLD) Workshop summary. American journal of respiratory and critical care medicine. 2001; 163:1256-1276. 
17. Kitada T, Asakawa S, Hattori N, Matsumine H, Yamamura Y, Minoshima S, Yokochi M, Mizuno Y and Shimizu N. Mutations in the parkin gene cause autosomal recessive juvenile parkinsonism. Nature. 1998; 392:605-608.

18. Lucking CB, Durr A, Bonifati V, Vaughan J, De Michele G, Gasser T, Harhangi BS, Meco G, Denefle P, Wood NW, Agid Y and Brice A. Association between earlyonset Parkinson's disease and mutations in the parkin gene. The New England journal of medicine. 2000; 342:1560-1567.

19. Winklhofer KF. Parkin and mitochondrial quality control: toward assembling the puzzle. Trends Cell Biol. 2014; 24:332-41. doi: 10.1016/j.tcb.2014.01.001.

20. Poulogiannis G, McIntyre RE, Dimitriadi M, Apps JR, Wilson CH, Ichimura K, Luo F, Cantley LC, Wyllie AH, Adams DJ and Arends MJ. PARK2 deletions occur frequently in sporadic colorectal cancer and accelerate adenoma development in Apc mutant mice. Proceedings of the National Academy of Sciences of the United States of America. 2010; 107:15145-15150.

21. Veeriah S, Taylor BS, Meng S, Fang F, Yilmaz E, Vivanco I, Janakiraman M, Schultz N, Hanrahan AJ, Pao W, Ladanyi M, Sander C, Heguy A, Holland EC, Paty PB, Mischel PS, et al. Somatic mutations of the Parkinson's diseaseassociated gene PARK2 in glioblastoma and other human malignancies. Nature genetics. 2010; 42:77-82.

22. Radulescu S, Ridgway RA, Appleton P, Kroboth K, Patel S, Woodgett J, Taylor S, Nathke IS and Sansom OJ. Defining the role of APC in the mitotic spindle checkpoint in vivo: APC-deficient cells are resistant to Taxol. Oncogene. 2010; 29:6418-6427.

23. Wang F, Denison S, Lai JP, Philips LA, Montoya D, Kock N, Schule B, Klein C, Shridhar V, Roberts LR and Smith DI. Parkin gene alterations in hepatocellular carcinoma. Genes, chromosomes \& cancer. 2004; 40:85-96.

24. Xiong D, Wang Y, Kupert E, Simpson C, Pinney SM, Gaba CR, Mandal D, Schwartz AG, Yang P, de Andrade M, Pikielny C, Byun J, Li Y, Stambolian D, Spitz MR, Liu $\mathrm{Y}$, et al. A recurrent mutation in PARK2 is associated with familial lung cancer. American journal of human genetics. 2015; 96:301-308.

25. Frank-Cannon TC, Tran T, Ruhn KA, Martinez TN, Hong J, Marvin M, Hartley M, Trevino I, O'Brien DE, Casey B, Goldberg MS and Tansey MG. Parkin deficiency increases vulnerability to inflammation-related nigral degeneration. The Journal of neuroscience. 2008; 28:10825-10834.

26. Rom O, Avezov K, Aizenbud D and Reznick AZ. Cigarette smoking and inflammation revisited. Respiratory physiology \& neurobiology. 2013; 187:5-10.

27. Hah N, Benner C, Chong LW, Yu RT, Downes M and Evans RM. Inflammation-sensitive super enhancers form domains of coordinately regulated enhancer RNAs. Proceedings of the National Academy of Sciences of the United States of America. 2015; 112:E297-302.
28. Palacino JJ, Sagi D, Goldberg MS, Krauss S, Motz C, Wacker M, Klose J and Shen J. Mitochondrial dysfunction and oxidative damage in parkin-deficient mice. The Journal of biological chemistry. 2004; 279:18614-18622.

29. Zhang C, Lin M, Wu R, Wang X, Yang B, Levine AJ, Hu $\mathrm{W}$ and Feng Z. Parkin, a p53 target gene, mediates the role of p53 in glucose metabolism and the Warburg effect. Proceedings of the National Academy of Sciences of the United States of America. 2011; 108:16259-16264.

30. Zha L, Chen J, Sun S, Mao L, Chu X, Deng H, Cai J, Li X, Liu Z and Cao W. Soyasaponins can blunt inflammation by inhibiting the reactive oxygen speciesmediated activation of PI3K/Akt/NF-kB pathway. PloS one. 2014; 9:e107655.

31. Lee SB, Kim JJ, Chung JS, Lee MS, Lee KH, Kim BS and Do Yoo Y. Romol is a negative-feedback regulator of Myc. Journal of cell science. 2011; 124:1911-1924.

32. Wang BJ, Sheu HM, Guo YL, Lee YH, Lai CS, Pan MH and Wang YJ. Hexavalent chromium induced ROS formation, Akt, NF-kappaB, and MAPK activation, and TNF-alpha and IL-1alpha production in keratinocytes. Toxicology letters. 2010; 198:216-224.

33. Yang J, Li Q, Zhou XD, Kolosov VP and Perelman JM. Naringenin attenuates mucous hypersecretion by modulating reactive oxygen species production and inhibiting NF-kappaB activity via EGFR-PI3K-Akt/ERK MAPKinase signaling in human airway epithelial cells. Molecular and cellular biochemistry. 2011; 351:29-40.

34. Lee SB, Kim JJ, Nam HJ, Gao B, Yin P, Qin B, Yi SY, Ham H, Evans D, Kim SH, Zhang J, Deng M, Liu T, Zhang H, Billadeau DD, Wang L, et al. Parkin Regulates Mitosis and Genomic Stability through Cdc20/Cdh1. Molecular cell. 2015; 60:21-34.

35. Jechlinger $M$. Organotypic culture of untransformed and tumorigenic primary mammary epithelial cells. Cold Spring Harbor protocols. 2015; 2015:457-461.

36. Haycock JW. 3D cell culture: a review of current approaches and techniques. Methods Mol Biol. 2011; 695:1-15.

37. Houghton AM. Mechanistic links between COPD and lung cancer. Nature reviews Cancer. 2013; 13:233-245.

38. Moghaddam SJ, Barta P, Mirabolfathinejad SG, AmmarAouchiche Z, Garza NT, Vo TT, Newman RA, Aggarwal BB, Evans CM, Tuvim MJ, Lotan R and Dickey BF. Curcumin inhibits COPD-like airway inflammation and lung cancer progression in mice. Carcinogenesis. 2009; 30:1949-1956.

39. Bao Z, Xiong J, Li W, Chen Z, Shen H and Ying S. Genomic instability in chronic airway inflammatory diseases. Biomedical journal. 2015; 38:117-124.

40. Benjamini $\mathrm{Y}$ and Hochberg Y. Controlling the False Discovery Rate: A Practical and Powerful Approach to Multiple Testing. Journal of the Royal Statistical Society Series B (Methodological). 57:289-300.

41. Team RC. (2014). R: A language and environment for statistical computing. (Vienna, Austria.: R Foundation for Statistical Computing). 
42. Tibshirani R. Regression Shrinkage and Selection via the Lasso. Journal of the Royal Statistical Society (Series B). 1996; 58:267-288.

43. Barrett JC, Fry B, Maller J and Daly MJ. Haploview: analysis and visualization of LD and haplotype maps. Bioinformatics. 2005; 21:263-265.

44. Young R, Hopkins R, Etzel C and El-Zein R. Genetics of lung cancer susceptibility and COPD. The Lancet Oncology. 2011; 12:622-623.

45. Tracy RP. 'Deep phenotyping': characterizing populations in the era of genomics and systems biology. Current opinion in lipidology. 2008; 19:151-157.

46. Curjuric I, Imboden M, Nadif R, Kumar A, Schindler C, Haun M, Kronenberg F, Kunzli N, Phuleria H, Postma DS, Russi EW, Rochat T, Demenais F and Probst-Hensch NM. Different genes interact with particulate matter and tobacco smoke exposure in affecting lung function decline in the general population. PloS one. 2012; 7:e40175.

47. Goldberg MS, Fleming SM, Palacino JJ, Cepeda C, Lam HA, Bhatnagar A, Meloni EG, Wu N, Ackerson LC, Klapstein GJ, Gajendiran M, Roth BL, Chesselet MF, Maidment NT, Levine MS and Shen J. Parkindeficient mice exhibit nigrostriatal deficits but not loss of dopaminergic neurons. The Journal of biological chemistry. 2003; 278:43628-43635.

48. Travis WD, World Health Organization., International Agency for Research on Cancer., International Association for the Study of Lung Cancer. and International Academy of Pathology. (2004). Pathology and genetics of tumours of the lung, pleura, thymus and heart. (LyonOxford:IARC PressOxford University Press (distributor)).

49. Haughney J, Gruffydd-Jones K, Roberts J, Lee AJ, Hardwell A and McGarvey L. The distribution of COPD in UK general practice using the new GOLD classification. The European respiratory journal. 2014; 43:993-1002.

50. de Andrade M, Li Y, Marks RS, Deschamps C, Scanlon PD, Olswold CL, Jiang R, Swensen SJ, Sun Z, Cunningham JM, Wampfler JA, Limper AH, Midthun DE and Yang P. Genetic variants associated with the risk of chronic obstructive pulmonary disease with and without lung cancer. Cancer prevention research. 2012; 5:365-373.

51. Sun Z, Aubry MC, Deschamps C, Marks RS, Okuno SH, Williams BA, Sugimura H, Pankratz VS and Yang P. Histologic grade is an independent prognostic factor for survival in non-small cell lung cancer: an analysis of 5018 hospital- and 712 population-based cases. The Journal of thoracic and cardiovascular surgery. 2006; 131:1014-1020.

52. Swensen SJ, Jett JR, Sloan JA, Midthun DE, Hartman TE, Sykes AM, Aughenbaugh GL, Zink FE, Hillman SL, Noetzel GR, Marks RS, Clayton AC and Pairolero PC. Screening for lung cancer with low-dose spiral computed tomography. American journal of respiratory and critical care medicine. 2002; 165:508-513.

53. Firth D. Bias reduction of maximum likelihood estimates. Biometrika. 1993; 80:11. 